\title{
Contemplation on new drug approvals by U.S. FDA, 2011-2015
}

\author{
Bhaven C. Kataria*, Ashwin K. Panchasara, Ashna S. Pandya, \\ Pavan J. Panchal, Mitul R. Parmar
}

Department of Pharmacology, GMERS Medical College, Sola, Ahmedabad-380060, Gujarat, India

Received: 4 January 2016

Revised: 14 January 2016

Accepted: 25 January 2016

*Correspondence to:

Dr. Bhaven C. Kataria,

Email: drbkataria@gmail.com

Copyright: (C) the author(s), publisher and licensee Medip Academy. This is an openaccess article distributed under the terms of the Creative Commons Attribution NonCommercial License, which permits unrestricted noncommercial use, distribution, and reproduction in any medium, provided the original work is properly cited.

\begin{abstract}
Background: The U.S Food and Drugs Administration (FDA) is the world's leading drug regulatory authority. There are reports of more product pipelines in oncology therapy area. The objective of this study was to see the overall trends of new drug approvals by the U.S. FDA in last 5 years and find the therapeutic areas with higher new drug approvals.

Methods: New drug approvals data obtained from publicly available databases of the U.S. FDA from 2011 through 2015. For the drug products identified, the drugs were classified into fourteen main Anatomical Therapeutic Chemical (ATC) groups, single or combination products, New Drug Application (NDA) chemical types, review classification and approval date.

Results: There were 182 new drugs approved from 2011 through 2015 by the U.S. FDA with a mean of 36.4 approvals per year. Out of these 182 new drug approvals, $149(81.87 \%)$ approvals were for new molecular entity (NME) and $33(18.13 \%)$ for biologics license application (BLA). There were more number of new drug approvals in antineoplastic and immunomodulating agents (L) ATC group ( $n=66 ; 36.26 \%$ of total new drug approvals).

Conclusions: For new drugs approved between 2011 and 2015, the U.S. FDA was first to approve majority of new drugs. There was upward trend of new drug approvals in antineoplastic therapeutic area.
\end{abstract}

Keywords: New molecular entity, ATC group, New drug, Regulatory, Biologics license application

\section{INTRODUCTION}

Regulatory authority plays an important role in approval of new drugs. The U.S Food and Drugs Administration (FDA) is the world's leading drug regulatory authority with a reputation and proven track record for being a leader in product safety and quality. Drug regulatory authorities of many other countries follow U.S. FDA regulatory guidelines.

New drugs are often innovative products that serve previously unmet medical needs or otherwise significantly help to advance patient care and public health. Drug innovation is a key to medical advances, especially in deadly diseases such as cancer. According to the IMS Institute for Healthcare Informatics report, there are more oncology products in pipelines. Pharmaceutical company investments remain high and cancer therapies account for more than $30 \%$ of all preclinical and phase 1 clinical development, with 21 new molecular entities being launched and reaching patients in the last two years alone. ${ }^{1}$ Oncology drugs still a pipeline priority according to the Pharmaceutical Research and Manufacturers of America (PhRMA), 771 new drugs and vaccines are in development by US companies; these agents are currently in clinical trials or have been submitted to the FDA for review. ${ }^{2}$

The objective of this study was to see the trends of new drug approvals by the U.S. FDA in last 5 years and find the therapeutic areas with higher new drug approvals.

\section{METHODS}

We obtained information about regulatory approvals by the U.S. FDA from publicly accessible databases at Drugs@FDA.3 The definition of "new drug" included 
new molecular entities (NMEs) and new biologics. The information about original new drug approvals (NDAs and BLAs) was retrieved by month from January 2011 to December 2015. All applications approved by FDA for the first time during the selected month include new molecular entities and new biologics. These analyses don't include original abbreviated new drug approvals (ANDAs) and supplemental approvals to NDAs and BLAs. The information from the FDA website was entered and analysed using a Microsoft Excel worksheet (Microsoft Office 2010).

For the drug products identified the following features were recorded: the ATC code as per WHO Anatomical Therapeutic Chemical (ATC) classification, single or combination product, NDA chemical types [1- New molecular entity, 2- New active ingredient, 3- New dosage form, 4- New combination, 5- New formulation or new manufacturer, 6- New indication, 7- Drug already marketed without an approved NDA, 8- OTC (over-thecounter) switch, 10- New indication submitted as distinct NDA - not consolidated], review classification (priority review drug, standard review drug, orphan drug) and approval date. ${ }^{4}$ For further analysis of data in this study, we included only FDA approvals for NDA chemical type 1 (new molecular entity). New drug approvals data further analysed as per drug designation (First-in-class, Orphan, Fast track, Breakthrough, Priority review, Accelerated approval, Met PDUFA target dates, First cycle, First Approved in U.S.) by U.S. FDA. ${ }^{5}$

\section{RESULTS}

The study identified total 182 new drug approvals by the U.S. FDA from 2011 to 2015, with a mean of 36.4 approvals per year. The year-wise distribution of total number of NME / new BLA approvals is shown in Figure 1. Out of these 182 new drug approvals, $149(81.87 \%)$ approvals were for NME and $33(18.13 \%)$ for BLA.

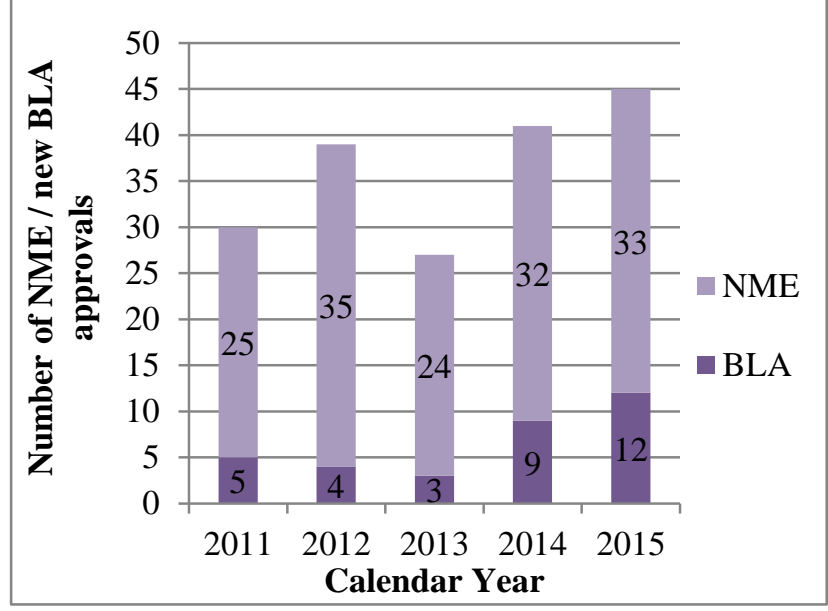

NME: New Molecular Entity; BLA: Biologics License Application.

Figure 1: FDA approvals per year, 2011-2015 (n=182).

A list of new drugs approved by U.S. FDA during 20112015 is presented in Table 1. The list is categorized in terms of ATC classification. Figure 2 shows the new drug approvals for each group of ATC classification. There are more number of new drug approvals in antineoplastic and immunomodulating agents (L) ATC group ( $n=66$; $36.26 \%$ of total new drug approvals).

Twelve fixed-dose combinations were approved during 2011-2015. New drug approval as per drug designation by U.S. FDA is presented in Table 2. There is more number of new drug approvals for rare or orphan diseases ( 21 of $45 ; 47 \%$ ) in 2015 as compared to previous years (2011-2014). About two-thirds of the novel drugs approved in 2015 (29 of 45, 64\%) were approved in the U.S. before receiving approval in any other country (Table 2).

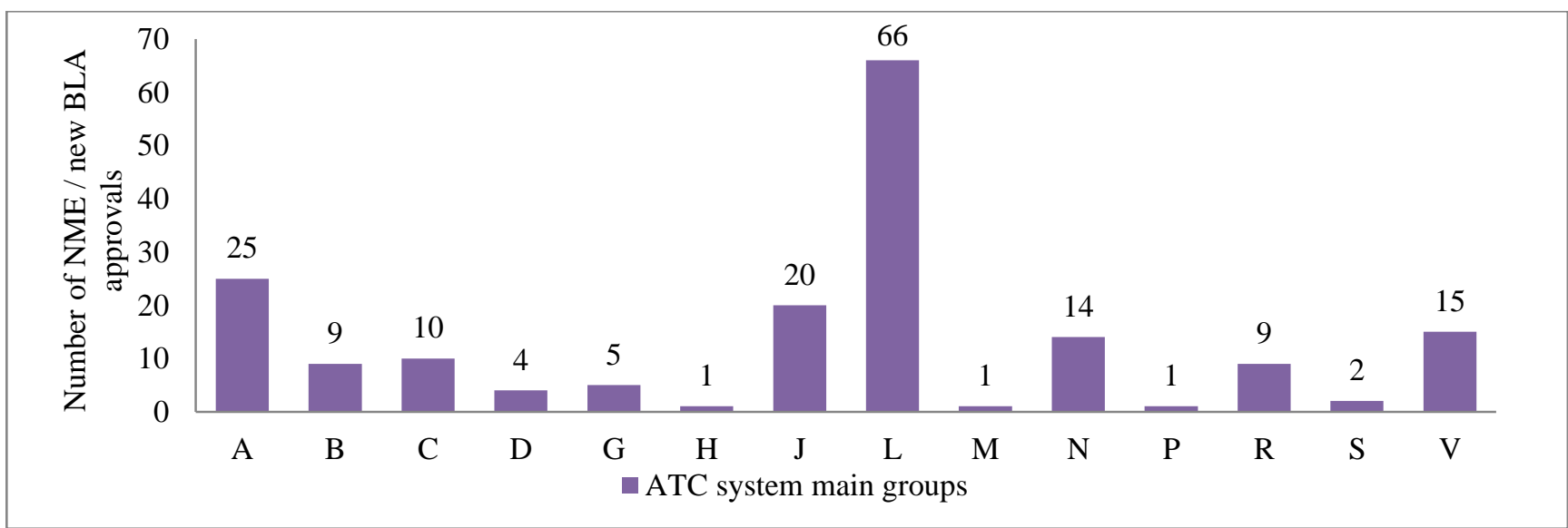

ATC Group: A (Alimentary tract and metabolism); B (Blood and blood forming organs); C (Cardiovascular system); D (Dermatologicals); G (Genito urinary system and sex hormones); H (Systemic hormonal preparations, excluding sex hormones and insulins); J (Antiinfectives for systemic use); L (Antineoplastic and immunomodulating agents); M (Musculo-skeletal system); N (Nervous system); P (Antiparasitic products, insecticides and repellents); R (Respiratory system); S (Sensory organs); V (Various).

Figure 2: Number of new drug approvals as per ATC classification, 2011-2015 (n=182). 
Table 1: New drug approvals as per ATC system main groups, 2011-2015.

\begin{tabular}{|c|c|}
\hline ATC system & Approved new drugs \\
\hline $\begin{array}{l}\text { A: Alimentary tract and } \\
\text { metabolism }\end{array}$ & $\begin{array}{l}\text { Linagliptin, Fidaxomicin, Taliglucerase Alfa, Lorcaserin Hydrochloride, Citric } \\
\text { Acid+Magnesium Oxide+Sodium Picosulfate, Linaclotide, Teduglutide Recombinant, } \\
\text { Crofelemer, Alogliptin Benzoate, Canagliflozin, Dapagliflozin Propanediol, Metreleptin, } \\
\text { Albiglutide, Empagliflozin, Canagliflozin+Metformin Hydrochloride, Eliglustat Tartrate, } \\
\text { Dulaglutide, Netupitant+Palonosetron Hydrochloride, Cholic Acid, Deoxycholic Acid, } \\
\text { Eluxadoline, Rolapitant Hydrochloride, Insulin Degludec, Asfotase Alfa, Sebelipase Alfa }\end{array}$ \\
\hline $\begin{array}{l}\text { B: Blood and blood } \\
\text { forming organs }\end{array}$ & $\begin{array}{l}\text { Rivaroxaban, Ticagrelor, Icatibant Acetate, Peginesatide Acetate, Apixaban, Vorapaxar } \\
\text { Sulfate, Edoxaban Tosylate, Cangrelor, Selexipag }\end{array}$ \\
\hline $\begin{array}{l}\text { C: Cardiovascular } \\
\text { system }\end{array}$ & $\begin{array}{l}\text { Azilsartan Kamedoxomil, Icosapent Ethyl, Mipomersen Sodium, Riociguat, Macitentan, } \\
\text { Droxidopa, Ivabradine Hydrochloride, Sacubitril+Valsartan, Alirocumab, Evolocumab }\end{array}$ \\
\hline D: Dermatologicals & Ingenol Mebutate, Luliconazole, Efinaconazole, Tavaborole \\
\hline $\begin{array}{l}\text { G: Genito urinary } \\
\text { system and sex } \\
\text { hormones }\end{array}$ & $\begin{array}{l}\text { Avanafil, Mirabegron, Ospemifene, Bazedoxifene Acetate+Conjugated Estrogens, } \\
\text { Flibanserin }\end{array}$ \\
\hline $\begin{array}{l}\text { H: Systemic hormonal } \\
\text { preparations, excl. Sex } \\
\text { hormones and insulins }\end{array}$ & Pasireotide Diaspartate \\
\hline $\begin{array}{l}\text { J: Antiinfectives for } \\
\text { systemic use }\end{array}$ & $\begin{array}{l}\text { Boceprevir, Rilpivirine Hydrochloride, Telaprevir, } \\
\text { Cobicistat+Elvitegravir+Emtricitabine+Tenofovir Disoproxil Fumarate, Raxibacumab, } \\
\text { Bedaquiline Fumarate, Telavancin, Dolutegravir Sodium, Simeprevir Sodium, Sofosbuvir, } \\
\text { Dalbavancin Hydrochloride, Tedizolid Phosphate, Oritavancin Diphosphate, } \\
\text { Ledipasvir+Sofosbuvir, Finafloxacin, Peramivir, Avibactam Sodium+Ceftazidime, } \\
\text { Isavuconazonium Sulfate, Daclatasvir Dihydrochloride, } \\
\text { Cobicistat+Elvitegravir+Emtricitabine+Tenofovir Alafenamide Fumarate }\end{array}$ \\
\hline $\begin{array}{l}\text { L: Antineoplastic and } \\
\text { immunomodulating } \\
\text { agents }\end{array}$ & $\begin{array}{l}\text { Belimumab, Ipilimumab, Vandetanib, Abiraterone Acetate, Belatacept, Vemurafenib, } \\
\text { Brentuximab, Vedotin, Crizotinib, Ruxolitinib Phosphate, Asparaginase Erwinia } \\
\text { Chrysanthemi, Axitinib, Vismodegib, Pertuzumab, Carfilzomib, Enzalutamide, Bosutinib } \\
\text { Monohydrate, Teriflunomide, Regorafenib, Omacetaxine Mepesuccinate, Tofacitinib } \\
\text { Citrate, Cabozantinib S-Malate, Ponatinib Hydrochloride, Pomalidomide, Regorafenib, } \\
\text { Dabrafenib Mesylate, Trametinib Dimethyl Sulfoxide, Afatinib Dimaleate, Golimumab, } \\
\text { Tocilizumab, Obinutuzumab, Ibrutinib, Ibrutinib, Miltefosine, Apremilast, Ramucirumab, } \\
\text { Siltuximab, Ceritinib, Vedolizumab, Belinostat, Idelalisib, Pembrolizumab, Naloxegol } \\
\text { Oxalate, Apremilast, Pirfenidone, Nintedanib Esylate, Blinatumomab, Olaparib, } \\
\text { Nivolumab, Secukinumab, Palbociclib, Lenvatinib Mesylate, Panobinostat Lactate, } \\
\text { Nivolumab, Dinutuximab, Sonidegib Phosphate, Uridine Triacetate, Tipiracil } \\
\text { Hydrochloride+Trifluridine, Trabectedin, Mepolizumab, Cobimetinib Fumarate, } \\
\text { Osimertinib Mesylate, Daratumumab, Ixazomib Citrate, Necitumumab, Elotuzumab, } \\
\text { Alectinib }\end{array}$ \\
\hline $\begin{array}{l}\text { M: Musculo-skeletal } \\
\text { system }\end{array}$ & I \\
\hline N: Nervous system & $\begin{array}{l}\text { Vilazodone Hydrochloride, Gabapentin Enacarbil, Ezogabine, Clobazam, Perampanel, } \\
\text { Dimethyl Fumarate, Vortioxetine Hydrobromide, Eslicarbazepine Acetate, Tasimelteon, } \\
\text { Suvorexant, Tasimelteon, Brexpiprazole, Cariprazine Hydrochloride, Aripiprazole Lauroxil }\end{array}$ \\
\hline $\begin{array}{l}\text { P: Antiparasitic } \\
\text { products, insecticides } \\
\text { and repellents }\end{array}$ & e \\
\hline R: Respiratory system & $\begin{array}{l}\text { Roflumilast, Indacaterol Maleate, Ivacaftor, Lucinactant, Aclidinium Bromide, Fluticasone } \\
\text { Furoate+Vilanterol Trifenatate, Umeclidinium Bromide+Vilanterol Trifenatate, Olodaterol } \\
\text { Hydrochloride, Ivacaftor+Lumacaftor }\end{array}$ \\
\hline S: Sensory organs & Tafluprost, Ocriplasmin \\
\hline V: Various & $\begin{array}{l}\text { Ioflupane I-123, Gadobutrol, Deferiprone, Glucarpidase, Florbetapir F-18, Choline C-11, } \\
\text { Technetium TC-99M Tilmanocept, Gadoterate Meglumine, Radium Ra-223 Dichloride, } \\
\text { Flutemetamol F-18, Florbetaben F-18, Sulfur Hexafluoride Lipid-Type A Microspheres, } \\
\text { Idarucizumab, Patiromer Sorbitex Calcium, Sugammadex }\end{array}$ \\
\hline
\end{tabular}


Table 2: New drug approvals as per drug designation by U.S. FDA, 2011-2015 (in \%).

\begin{tabular}{|c|c|c|c|c|c|c|c|c|c|}
\hline Year & $\begin{array}{l}\text { First in } \\
\text { Class }\end{array}$ & Orphan & $\begin{array}{l}\text { Fast } \\
\text { Track }\end{array}$ & $\begin{array}{l}\text { Break- } \\
\text { through }\end{array}$ & $\begin{array}{l}\text { Priority } \\
\text { Review }\end{array}$ & $\begin{array}{l}\text { Accelerated } \\
\text { Approval }\end{array}$ & $\begin{array}{l}\text { Met } \\
\text { PDUFA } \\
\text { Target } \\
\text { Dates }\end{array}$ & $\begin{array}{l}\text { First } \\
\text { Cycle }\end{array}$ & $\begin{array}{l}\text { First } \\
\text { Approved in } \\
\text { U.S. }\end{array}$ \\
\hline 2011 & 40 & 37 & 47 & - & 50 & 10 & 97 & 63 & 63 \\
\hline 2012 & 51 & 33 & 36 & - & 41 & 10 & 97 & 79 & 77 \\
\hline 2013 & 33 & 33 & 37 & 11 & 37 & 7 & 100 & 89 & 74 \\
\hline 2014 & 41 & 41 & 41 & 22 & 61 & 20 & 98 & 78 & 63 \\
\hline 2015 & 36 & 47 & 31 & 22 & 53 & 13 & 96 & 87 & 64 \\
\hline
\end{tabular}

First-in-Class: Drugs with a new and unique mechanism for treating a medical condition; Orphan Drugs: Drugs approved for small populations of patients with rare diseases; Fast Track: Drugs that can treat unmet medical needs; Breakthrough: A drug with preliminary clinical evidence demonstrating that it may result in substantial improvement on at least one clinically significant endpoint over available therapies; Priority Review: A drug is given a priority review if there is potential to provide a significant advance in existing medical care. Drugs assigned priority review under CDER's Priority Review Voucher program are not included in this summary; Accelerated Approval: Early approval based on markers that predict a reasonable benefit, with more testing to confirm clinical benefit after approval; PDUFA Goal Date: The goal date for application review determined by the Prescription Drug User Fee Act (PDUFA); First Cycle: Drugs that were approved without request for additional information that could delay approval and lead to another cycle of review; First Approved in U.S.: Drugs that were approved in the United States before approval in other country.

\section{DISCUSSION}

In last decade (from 2006 through 2014) U.S. FDA averaged about 28 novel drug approvals per year. ${ }^{6}$ There is a continuing upward trend for the annual number of novel drug approvals (36.4 approvals per year in last 5 years). During the last 5 years, submissions of applications for NMEs and novel new BLAs by the pharmaceutical industry have remained relatively stable. U.S. FDA used a number of regulatory methods (fast track, breakthrough, priority review, and accelerated approval) to expedite the approval of novel drugs. Regulatory processes differ widely between U.S. FDA and regulatory agencies in other countries. But because of specific regulatory methods used by FDA, majority of the novel drugs approved in the U.S. before receiving approval in any other country.

There is a clear upward trend of more novel drug development for cancer treatments (66 of 182, 36.26\%) and for diabetes. First-in-Class approval by U.S. FDA is one indicator of the innovative nature of a drug. These drugs often have mechanisms of action different from those of existing therapies. FDA identified 16 of the 45 novel drugs approved in 2015 (36\%) as first-in-class. Some of first-in-class approval during 2011-2015 includes sugammadex to reverse post-surgical neuromuscular blockade caused by certain kinds of anesthesia, palbociclib to treat advanced breast cancer, ledipasvir/sofosbuvir to treat certain patients with chronic hepatitis $\mathrm{C}$, pembrolizumab for patients with unresectable or metastatic melanoma, canagliflozin for type 2 diabetes glycemic control, ado-trastuzumab emtansine for HER2positive late-stage breast cancer, crofelemer for HIV associated diarrhea, bedaquiline to treat multi-drugresistant pulmonary tuberculosis and glucarpidase, an important new treatment option for cancer patients to help them avoid the toxic effects of the drug methotrexate.
In 2015, The U.S. FDA approved flibanserin to treat acquired, generalized hypoactive sexual desire disorder (HSDD) in premenopausal women. Prior to flibanserin's approval, there were no FDA-approved treatments for sexual desire disorders in men or women. ${ }^{7}$ About $47 \%$ of the new drugs approved by U.S. FDA in 2015 (21 of 45) were approved to treat rare or orphan diseases. This is significant because patients with rare diseases often have few or no drugs available to treat their conditions. Some of noteworthy examples of drugs to treat rare diseases among the 2015 novel drugs include: sebelipase alfa to treat lysosomal acid lipase deficiency, lumacaftor/ivacaftor for cystic fibrosis, dinutuximab to treat pediatric patients with high-risk neuroblastoma, uridine triacetate to treat patients with hereditary orotic aciduria.

In conclusion, our analysis of new drugs approved between 2011 and 2015 shows that the FDA has provided more rapid reviews of applications as vast majority of the new drugs first received approval for use in the U.S. Our findings confirm upward trend of new drug approvals in antineoplastic therapeutic area.

\section{Funding: No funding sources Conflict of interest: None declared Ethical approval: Not required}

\section{REFERENCES}

1. IMS Institute for Healthcare Informatics. Innovation in Cancer Care and Implications for Health Systems May 2014. Available at www.obroncology.com/imshealth/content/IMSH_O ncology_Trend_Report_020514F4_screen.pdf. Accessed 2 January 2016.

2. Pharmaceutical Research and Manufacturers of America. Nearly 800 New Medicines in Development to Help in the Fight against Cancer. 
October 6, 2014. Available at www.phrma.org/research/cancer. Accessed 2 January 2016.

3. U.S. Food and Drug Administration. Drug Approval Reports. Available at www.accessdata.fda.gov/scripts/cder/drugsatfda/ind ex.cfm?fuseaction=Reports.ReportsMenu. Accessed 1 January 2016.

4. WHO Collaborating Centre for Drug Statistics Methodology, ATC/DDD Index 2016. Available at www.whocc.no/atc_ddd_index/. Accessed 3 January 2016.

5. U.S. Food and Drug Administration. New Drugs at FDA: CDER's New Molecular Entities and New Therapeutic Biological Products. Available at www.fda.gov/Drugs/DevelopmentApprovalProcess/
DrugInnovation/default.htm. Accessed 3 January 2016.

6. U.S. Food and Drug Administration. New Molecular Entity and New Therapeutic Biological Product Approvals for 2015. Available at www.fda.gov/downloads/Drugs/DevelopmentAppro valProcess/DrugInnovation/UCM481709.pdf. Accessed 3 January 2016.

7. McCarthy M. US drug agency approves drug for low sexual desire in women. BMJ. 2015;351:h4522.

Cite this article as: Kataria $\mathrm{BC}$, Panchasara AK, Pandya AS, Panchal PJ, Parmar MR. Contemplation on new drug approvals by U.S. FDA, 2011-2015. Int J Basic Clin Pharmacol 2016;5:55-9. 